\title{
Características clínicas e epidemiológicas de crianças com infecção por SARS-CoV2
}

\author{
Clinical and epidemiological characteristics of children with SARS-CoV2 infection \\ Características clínicas y epidemiológicas de niños con infección por SARS-CoV2 \\ Maria Lucia Barbosa Maia dos Santos ${ }^{1}$ (D) https://orcid.org/0000-0002-8821-3240 \\ Ana Cristina dos Santos Monteiro ${ }^{1}$ (D) https://orcid.org/0000-0001-8803-2688 \\ Angela Midori Matuhara ${ }^{1}$ (D) https://orcid.org/0000-0001-8181-7837 \\ Shieley Elaine Ferreira ${ }^{1}$ (D) https://orcid.org/0000-0003-0621-0052 \\ Sara Ferreira dos Santos ${ }^{1}$ (D) htps://orcid.org/0000-0002-2987-8066 \\ Adriana Aparecida Cabral de Melo ${ }^{1}$ (D) https://orcid.org/0000-0001-8821-7308 \\ Simone Aparecida Lima Pavani ${ }^{1}$ (D) https://orcid.org/0000-0003-0534-3865 \\ Juliana Caires de Oliveira Achili Ferreira ${ }^{1}$ (D) https://orcid.org/0000-0002-9249-2318
}

\section{Resumo}

Um novo coronavírus descoberto em dezembro de 2019 ocasionou uma pandemia com resultados alarmantes de morbimortalidade. Este artigo de revisão de escopo segundo metodologia do Instituto Joanna Briggs, descreve características clínicas e epidemiológicas de crianças com infecção por SARS-CoV2. Os artigos evidenciaram que crianças apresentam a doença de forma assintomática e/ou oligossintomática, com baixa mortalidade e poucas complicações, e como os sintomas não são tão típicos quanto nos adultos, é necessário um diagnóstico de COVID-19 baseado nos achados de imagem, juntamente com o histórico epidemiológico e pesquisa em swab orofaríngeo, fezes e urina. As autoras discorrem sobre cuidados aos pacientes hospitalizados e medidas específicas para o combate ao SARS-CoV-2, a fim de manter a saúde física e emocional dos profissionais, e continuidade do cuidado seguro e de qualidade.

\section{Abstract}

A new coronavirus discovered in December 2019 was responsible for a pandemic with alarming results of morbidity and mortality. Fever, dry cough, rhinorrhea, fatigue, and lymphopenia affects adults significantly while children have milder conditions. This review article describes clinical and epidemiological characteristics of children with SARS-CoV2 infection through the review of scope according to Joanna Briggs Institute methodology. The articles showed that children present disease asymptomatically and/or oligosymptomatically, with low mortality and few complications, and as the symptoms are not as typical as in adults, a diagnosis of VOCID-19 based on imaging findings, along with epidemiological history and research in oropharyngeal swab, feces and urine is required. The authors discuss the care of hospitalized patients and specific measures to combat SARS-CoV-2 in order to maintain the physical and emotional health of professionals, and continuity of safe and quality care.

\section{Resumen}

Un nuevo coronavirus descubierto en diciembre de 2019 causó una pandemia con resultados alarmantes de morbilidad y mortalidad. La fiebre, la tos seca, la rinorrea, la fatiga y la linfopenia afectan significativamente a los adultos, mientras que los niños tienen condiciones más leves. En este artículo de revisión se describen las características clínicas y epidemiológicas de los niños con infección por SARS-CoV2, revisando el alcance según la metodología del Instituto Joanna Briggs. Los artículos mostraron que los niños presentan la enfermedad de manera asintomática y/u oligosintomática, con baja mortalidad y pocas complicaciones, y como los síntomas no son tan típicos como en los adultos, se requiere un diagnóstico de VOCID-19 basado en los hallazgos de las imágenes, junto con la historia epidemiológica y la investigación en el hisopo orofaríngeo, las heces y la orina. Los autores examinan la atención de los pacientes hospitalizados y las medidas específicas para combatir el SRAS-CoV-2 a fin de mantener la salud física y emocional de los profesionales y la continuidad de una atención segura y de calidad.

\section{Descritores}

Enfermagem pediátrica; 2019-nCoV; COVID-19; Crianças; Coronavírus; Recém-nascido; SARS-CoV2; Perfil de saúde

\section{Keywords}

Pediatric nursing; 2019-nCoV; COVID-19; Children; Coronavirus; Infant; Newborn; SARS-CoV2; Health profile

\section{Descriptores}

Enfermería pediátrica; 2019-nCoV; COVID-19; Niños; Coronavirus; Bebé; Recién nacido; SARS-CoV2; Perfil de salud

\section{Como citar:}

Santos ML, Monteiro AC, Matuhara AM, Ferreira SE, Santos SF, Melo AA, et al. Características clínicas e epidemiológicas de crianças com infecção por SARS-CoV2 Rev Soc Bras Enferm Ped. 2020;20(Especial COVID-19):26-35.

\footnotetext{
${ }^{1}$ Instituto da Criança e do Adolescente, Hospital das Clínicas, Faculdade de Medicina, Universidade de São Paulo, São Paulo, SP, Brasil.
}

Conflitos de interesse: nada a declarar.

Submetido: 11 de Julho de 2020 | Aceito: 18 de Setembro de 2020

Autor correspondente: Juliana Caires de Oliveira Achili Ferreira | E-mail: juliana.caires@hc.fm.usp.br

DOI: http://dx.doi.org/10.31508/1676-3793202000000124 


\section{Introdução}

Em dezembro de 2019 foram diagnosticados casos de pneumonias por um novo coronavírus com início na China e, em 11 de fevereiro de 2020, o alarmante número de casos acarretou na declaração de pandemia pela Organização Mundial da Saúde (OMS).(1)

Coronavírus é uma família de vírus que causa infecções respiratórias. Isolados pela primeira vez em 1937, foram descritos como coronavírus somente em 1995, em decorrência do perfil na microscopia, por parecer uma coroa. O novo agente descoberto em 31/12/19 foi oficialmente nomeado pelo International Committee on Taxonomy of Viruses por Coronavírus SARS-Cov-2, pertencente à linhagem beta-coronavírus $2 \beta$ na árvore filogenética, responsável pela infecção em humanos e animais. ${ }^{(1)}$

O período de incubação varia 2 a 14 dias para o aparecimento dos primeiros sintomas, a transmissão ocorre apenas enquanto persistirem os sintomas, por gotículas contendo o vírus quando a paciente tosse, fala ou espira, e contato com objetos contaminados como brinquedos, maçaneta de portas. Outra via potencial de transmissão é eliminação do vírus pelas fezes. ${ }^{(1,2-8)}$

O novo Coronavírus SARS-CoV-2 pode sobreviver na urina por 10 dias em temperatura ambiente a $24^{\circ} \mathrm{C}$, por mais de 5 dias em secreções e fezes de pacientes com diarréia e cerca de 15 dias no sangue. . $^{(1,2)}$ É sensível à temperatura, pode sobreviver por 4 dias a $37^{\circ} \mathrm{C}$, por 90 minutos em temperatura de $56^{\circ} \mathrm{C}$, por 30 minutos em temperatura $75^{\circ} \mathrm{C}$. Ele pode ser inativado após $5 \mathrm{mi}-$ nutos de forma efetiva por éter, álcool a $75 \%$, desinfetante a base de cloro, ácido peracético ou clorofórmio.(2)

A infecção por SARS-CoV-2 afeta principalmente o trato respiratório, e as principais manifestações clínicas são febre, tosse seca, rinorréia, fadiga e linfopenia, pode resultar em síndrome respiratória aguda grave (SARS) e até morte em casos graves. ${ }^{(1,3)}$ Relatos da literatura afirmam que o vírus pode acometer vários órgãos, como: pulmões, fígado, rim e sistema nervoso central. Todavia, vários estudos realizados em diferentes populações e faixas etárias demonstraram que uma proporção significativa dos casos de infecção por SARS-CoV-2 foi diagnosticada sem apresentar sintomas ou com apresentações muito leves. ${ }^{(4-6)}$

Diferente dos adultos, as crianças desenvolvem a doença de forma leve e/ou assintomática, como prin- cipais sintomas clínicos a febre e tosse. Apesar da menor gravidade, a doença pode cursar de forma grave e levar a óbito em menor proporção, quando comparado aos adultos. Ademais, apesar de assintomáticos ou oligossintomáticos, bebês e crianças infectados podem ter altas cargas virais em suas nasofaringes, além de eliminar o vírus nas fezes por períodos mais longos. ${ }^{(7,8)}$

A menor gravidade da doença apresentada pelas crianças pode ser explicada pela suposta teoria que envolve a expressão da enzima conversora de angiotensina 2 (ECA2). Esse receptor, presente abundantemente no epitélio pulmonar, intestino delgado humano, endotélio vascular, pele, miocárdio e provavelmente no bulbo olfativo, tronco cerebral e córtex cerebral é o receptor da SARS-CoV-2, necessário para a entrada do vírus na célula hospedeira e subsequente replicação viral no organismo. ${ }^{(4)}$

A glicoproteína-S, presente na superfície do coronavírus, pode se ligar ao receptor ECA2 na superfície das células, principalmente nas células pulmonares, ricas em receptores ECA2. O ácido ribonucleico (RNA) do genoma viral é liberado dentro da célula, e a seguir, inicia-se a codificação de proteínas acessórias e estruturais, com posterior liberação de novos vírus. Esse processo tem como consequência a liberação de citocinas com intensa resposta inflamatória, causando insuficiência respiratória, choque e eventos tromboembólicos relacionados à coagulação intravascular disseminada. Portanto, uma expressão limitada da ECA2 na infância, período em que os pulmões ainda estão em desenvolvimento, poderia proteger as crianças da forma grave da doença. ${ }^{(4,8,9)}$

Mesmo sem a confirmação de que as mães com COVID-19 podem transmitir o SARS-CoV-2 através do leite materno, a OMS e a Sociedade Brasileira de Pediatria, fizeram recomendações para apoiar o aleitamento materno, composta por: higiene das mãos e uso de máscara facial antes de segurar o bebê em contato próximo. ${ }^{(10-12)}$

Apesar da falta de definição para as características clinicas e gravidade da doença, a grande maioria das pesquisas têm publicado dados de adultos, com literatura escassa de informações específicas para crianças, principalmente considerando as características de cada faixa etária.

A nova doença afeta diferentes grupos de indivíduos e cursa com gravidade variável. Contudo, embora crianças diagnosticadas com a nova infecção SARS-CoV2 em vários países terem apresentado a doença de forma leve e/ou assintomática, o grau de infecção e 
transmissão do vírus SRA-CoV-2 por crianças e jovens ainda não está claro. Diante do exposto é importante explorar a literatura para saber quais são os sintomas clínicos e os aspectos epidemiológicos apresentados pelas crianças com infecção pelo SARS-CoV2.

Os objetivos do estudo são: descrever as características clínicas e epidemiológicas de crianças diagnosticadas com infecção por SARS-CoV2 no período pandêmico; Identificar o tempo médio de internação das crianças com infecção por SARS-CoV2, e Identificar a frequência de óbito em crianças com infecção por SARS-CoV2.

\section{Métodos}

Essa revisão de escopo foi realizada segundo a metodologia do Instituto Joanna Briggs (JBI). ${ }^{(11)}$ A estratégia PCCT (paciente, conceito, contexto, tipo de estudo) orientou a construção da pergunta de revisão: "Quais são as características clínicas e epidemiológicas das crianças com infecção por SARS-CoV2?"

\section{Critérios de inclusão}

\section{Paciente}

Estudos primários com crianças de um mês a 18 anos de idade, de cor branca e não branca, de todas as raças, ambos os sexos, que foram diagnosticadas com infecção por SARS-CoV2, em swab de orofaringe, com início em dezembro de 2019.

\section{Conceito}

Pesquisas primárias com desfecho sobre características clínicas e perfil epidemiológico de crianças que foram diagnosticadas com infecção por SARS-CoV2, a partir de dezembro de 2019.

\section{Contexto}

Foram considerados estudos primários com desfecho sobre características clínicas, perfil epidemiológico, resultados de exames laboratoriais e de imagens de crianças diagnosticadas com infecção por SARS-CoV2, dentro e fora do ambiente hospitalar.

\section{Tipo de estudos}

Foram consideradas pesquisas com desenho de estudos experimental, quase-experimental, ensaios clínicos ran- domizados e não randomizados, estudos observacionais analíticos, como coorte prospectiva e/ou retrospectiva, estudo de caso controle, estudos descritivos, observacionais, série de relatos de casos, relatos de casos, carta ao Editor. Foram excluídos opinião de especialista.

\section{Estratégia de busca}

A estratégia de busca foi desenvolvida com orientação de uma bibliotecária, projetada para encontrar artigos de pesquisa publicados e não publicados. Todo o processo de revisão foi baseado na metodologia de revisão de escopo do JBI, ${ }^{(11)}$ conduzida em três etapas: primeiro foi realizada uma busca inicial limitada na Biblioteca Virtual em Saúde (BVS), Cumulative Index to Nursing and Allied Health Literature (CINAHL), Google Acadêmico, Pubmed e Web of Science; na sequência uma segunda pesquisa foi realizada usando todas as palavras-chave identificadas e os descritores em todas as bases de dados definidas para a pesquisa; a última etapa compreendeu uma terceira busca realizada nas listas de referências de todos os artigos que foram incluídos na revisão.

Foram utilizadas as seguintes combinações:

- PubMed: ("severe acute respiratory syndrome coronavirus 2"[Supplementary Concept] OR "severe acute respiratory syndrome coronavirus 2"[All Fields] OR "sars cov 2"[All Fields]) AND ("infan$\mathrm{t}^{\prime}$ [MeSH Terms] OR "child"[MeSH Terms] OR "adolescent" [MeSH Terms])

- CINAHL: (MH “SARS Virus") AND (MH "Child")

- EMBASE: \#2 'sars cov2':ab,ti AND children

- BVS: 'sars cov2 AND 2019-ncov AND Crianças

\section{Seleção dos estudos}

Após a pesquisa, todas as citações identificadas foram agrupadas em planilha no Excel ${ }^{\circledR}$ e as duplicatas removidas. Os títulos e resumos foram examinados por dois revisores independentes para avaliação, com base nos critérios de inclusão para a revisão. Estudos potencialmente relevantes foram recuperados na íntegra e seus detalhes de citação importados para o Sistema Joanna Briggs Institute de Gerenciamento Unificado, Avaliação e Revisão de Informações (JBISUMARI). As divergências que surgiram entre os revisores em cada etapa do processo de seleção dos estudos foram resolvidas por meio de discussão entre os mesmos ou com a participação de um terceiro revisor. 


\section{Extração dos dados}

Os dados quantitativos e qualitativos foram extraídos dos artigos por dois revisores independentes, usando uma ferramenta para extração de dados desenvolvida pelas autoras, conforme indicado pela metodologia de revisão de escopo proposta pelo JBI. Incluíram detalhes específicos sobre a população, conceito, contexto, tipo de estudo, métodos, resultados e conclusões relevantes para responder o objetivo da revisão. Não houve divergência nessa fase.

\section{Apresentação dos resultados}

Os resultados foram apresentados em forma de quadros, tabelas e figuras, de acordo com o desenho do estudo. Um resumo descritivo sintetizou os achados para fornecer uma descrição das evidências existentes relacionadas ao objetivo e à pergunta da revisão.

\section{Resultados}

Após análise por dois revisores independentes dos textos completos de 70 artigos encontrados inicial- mente evidenciou que 27 preencheram os critérios de elegibilidade, conforme figura 1 . Todos os estudos incluídos são relatos, série de relatos de casos ou coorte retrospectiva. $\mathrm{O}$ relato de casos com maior número de pacientes descreve as caraterísticas clínicas e epidemiológicas de 171 crianças com diagnóstico de SARS-CoV2 na China.

Os estudos, detalhados no quadro 1, compuseram uma amostra de 374 pacientes com mediana de idade de 10 anos (0.1-15) e todos descreveram as características clínicas e epidemiológicas, exames de imagens e laboratoriais dos pacientes diagnosticados com SARS-CoV2 no período pandêmico iniciado em dezembro de 2019, conforme descrito na tabela 1.

Todos os estudos foram publicados em 2020, sendo que $24(88,9 \%)$ foram publicados na China, 1 (3,7\%) na Coreia, 1 (3,7\%) por Singapura e 1(3,7\%) pelo Vietnã. Quanto ao desenho de estudo, 15 (55,5\%) foram relato de caso, $6(22,2 \%)$ série de relato de casos, 4 $(14,8 \%)$ estudos coorte retrospectiva, $1(3,7 \%)$ estudo de coorte observacional e 1 (3,7\%) carta ao Editor.

A figura 1 apresenta o processo de busca e seleção dos estudos desta revisão segundo fluxograma PRISMA:(11)

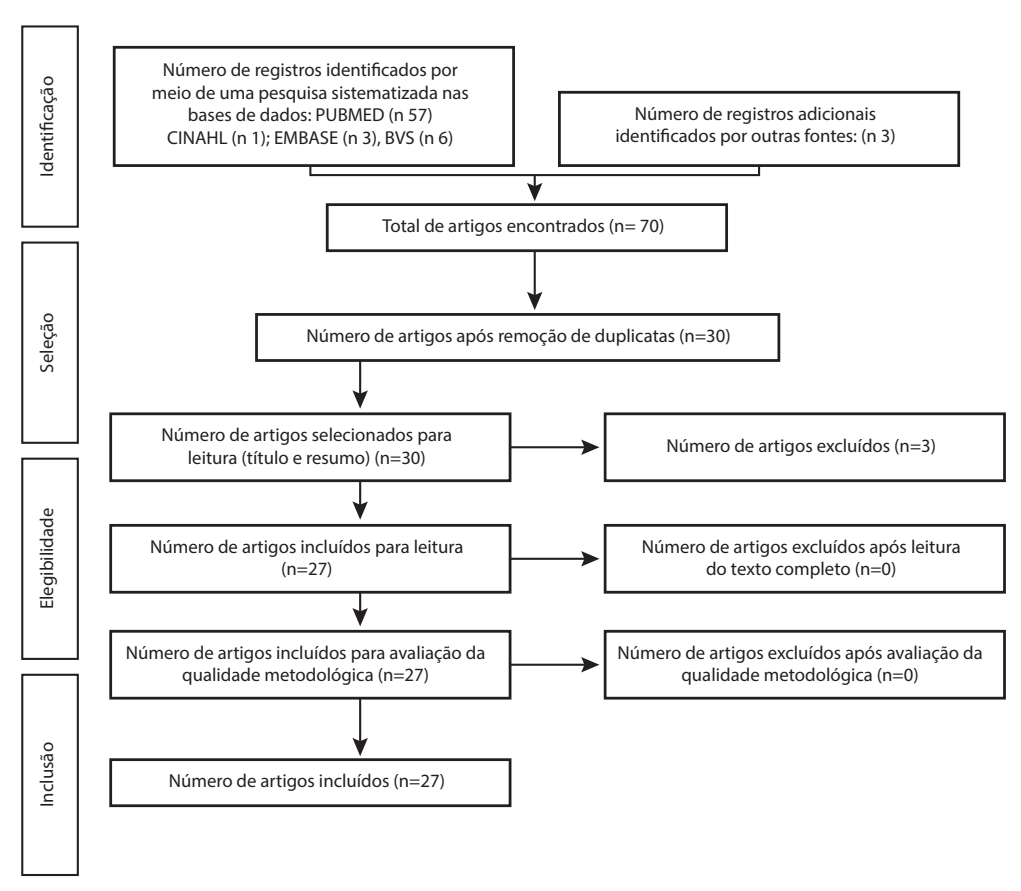

Figura 1. Fluxograma de seleção de artigos 
Quadro 1. Características dos estudos incluídos na revisão

\begin{tabular}{|c|c|c|c|c|c|c|}
\hline Autores & Amostra & \begin{tabular}{|l} 
Desenho do \\
estudo
\end{tabular} & Epidemiologia & Sinais clínicos & Exames de imagem & Exames laboratoriais \\
\hline $\begin{array}{l}\text { Cai J, et al }\left.\right|^{(13)} \\
\text { Clin Infect } \\
\text { China, } 2020\end{array}$ & $\begin{array}{l}10 \text { pacientes } \\
4 \text { do sexo } \\
\text { masculino } \\
6 \text { do sexo feminino } \\
\end{array}$ & \begin{tabular}{|l} 
Série de \\
relatos de \\
caso
\end{tabular} & $\begin{array}{l}\text { Contato com familiar } \\
\text { confirmado, e com } \\
\text { caso suspeitos, } \\
\text { Cluster familiar } \\
\end{array}$ & $\begin{array}{l}\text { Febre, tosse, dor de } \\
\text { garganta, congestão } \\
\text { nasal, rinorréia }\end{array}$ & Infiltrado irregular no RX tórax & $\begin{array}{l}\text { Leucocitose; } \\
\text { neutropenia, CKMB } \\
\text { elevada }\end{array}$ \\
\hline $\begin{array}{l}\text { Li Y, et al }{ }^{(14)} \\
\text { Pediatr Pulmonol. } \\
\text { China, } 2020\end{array}$ & $\begin{array}{l}2 \text { pacientes } \\
1 \text { sexo masculino } \\
1 \text { sexo feminino }\end{array}$ & $\begin{array}{l}\text { Relato de } \\
\text { caso }\end{array}$ & $\begin{array}{l}\text { Contato com } \\
\text { Membros da família } \\
\text { confirmados }\end{array}$ & Afebril, rinorreia, tosse & $\begin{array}{l}\text { Caso 1. Manchas nos dois } \\
\text { lobos superior e inferior } \\
\text { Caso 2. Feixes broncovasculares } \\
\text { aumentados e levemente } \\
\text { desordenados em ambos os } \\
\text { lados }\end{array}$ & $\begin{array}{l}\text { Caso 1. PCR } \\
11,2 \mathrm{mg} / \mathrm{dl} \text {, ácido } \\
\text { úrico } 212 \mu \mathrm{mol} / \mathrm{L} \text {, } \\
\text { Caso 2. Ácido úrico } \\
318 \mu \mathrm{mol} / \mathrm{L}, \mathrm{TC}:\end{array}$ \\
\hline $\begin{array}{l}\text { Ji LN, et al }{ }^{(15)} \\
\text { World J Pediatr } \\
\text { China, } 2020\end{array}$ & $\begin{array}{l}2 \text { pacientes do } \\
\text { sexo masculino }\end{array}$ & $\begin{array}{l}\text { Relato de } \\
\text { caso }\end{array}$ & $\begin{array}{l}\text { Caso } 1 \text { e 2. Viagem } \\
\text { para área epidêmica } \\
\text { e contato com colega } \\
\text { com COVID-19 }\end{array}$ & $\begin{array}{l}\text { Caso 1. Febre, } \\
\text { congestão faríngea, } \\
\text { infecção do trato } \\
\text { respiratório superior } \\
\text { Caso 2. Diarréia leve } \\
\text { por dois dias, sem } \\
\text { febre e tosse }\end{array}$ & Caso 1 e 2 TC de tórax normal & $\begin{array}{l}\text { Caso 1. PCR elevada } \\
\text { e leucocitose } \\
\text { Caso 2. PCR e } \\
\text { glóbulos bancos } \\
\text { normais }\end{array}$ \\
\hline $\begin{array}{l}\text { Park JY, et al }{ }^{(16)} \\
\text { J Korean Med Sci. } \\
\text { Coréia, } 2020\end{array}$ & $\begin{array}{l}1 \text { paciente do sexo } \\
\text { feminino }\end{array}$ & $\begin{array}{l}\text { Relato de } \\
\text { caso }\end{array}$ & $\begin{array}{l}\text { Viagem para área } \\
\text { epidêmica, contato } \\
\text { com familiar com } \\
\text { COVID-19 positivo }\end{array}$ & Febre & $\begin{array}{l}\text { Consolidações nodulares } \\
\text { irregulares, opacidade periférica } \\
\text { de vidro fosco em áreas } \\
\text { subpleurais do lobo inferior } \\
\text { direito }\end{array}$ & $\begin{array}{l}\text { Exames laboratoriais } \\
\text { normais }\end{array}$ \\
\hline $\begin{array}{l}\text { Cui Y et al(17) } \\
J \text { Infect Dis } \\
\text { China, } 2020\end{array}$ & $\begin{array}{l}1 \text { paciente de } 55 \\
\text { dias de vida } \\
\text { sexo não } \\
\text { informado }\end{array}$ & $\begin{array}{l}\text { Relato de } \\
\text { caso }\end{array}$ & $\begin{array}{l}\text { Contato com familiar } \\
\text { COVID-19 positivo, } \\
\text { viagem à área } \\
\text { endêmica }\end{array}$ & $\begin{array}{l}\text { Tosse, taquicardia } \\
\text { Hipoxemia, rinorreia }\end{array}$ & $\begin{array}{l}\text { Pneumonia } \\
\text { Opacidade em vidro fosco }\end{array}$ & $\begin{array}{l}\text { A-hidroxibutirato } \\
\text { desidrogenase, TGP, } \\
\text { Bilirrubina total, TGO, } \\
\text { e troponina elevados }\end{array}$ \\
\hline $\begin{array}{l}\text { Tang A, et al }\left.\right|^{(18)} \\
\text { Emerg Infect Dis J. } \\
\text { China } 2020\end{array}$ & $\begin{array}{l}1 \text { paciente do sexo } \\
\text { masculino }\end{array}$ & $\begin{array}{l}\text { Relato de } \\
\text { caso }\end{array}$ & Aglomeração familiar & Não informado & Tomografia de tórax normal & $\begin{array}{l}\text { Sem alterações dos } \\
\text { exames laboratoriais }\end{array}$ \\
\hline $\begin{array}{l}\text { Zhang YH, et al }{ }^{(19)} \\
\text { Zhonghua Er Ke Za } \\
\text { Zhi., China } 2020 \\
\end{array}$ & $\begin{array}{l}1 \text { paciente do sexo } \\
\text { masculino }\end{array}$ & \begin{tabular}{|l} 
Relato de \\
caso
\end{tabular} & $\begin{array}{l}\text { Viagem à área } \\
\text { endêmica }\end{array}$ & Tosse & $\begin{array}{l}\text { Tomografia de tórax, textura } \\
\text { de ambos os pulmões mais } \\
\text { espessa }\end{array}$ & $\begin{array}{l}\text { Exames laboratoriais } \\
\text { normais, urina e fezes } \\
\text { normais }\end{array}$ \\
\hline 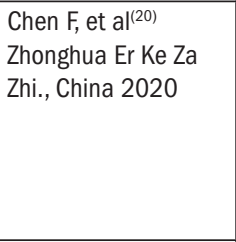 & $\begin{array}{l}1 \text { paciente do sexo } \\
\text { masculino } \\
\text { hidronefrose }\end{array}$ & $\begin{array}{l}\text { Relato de } \\
\text { caso }\end{array}$ & $\begin{array}{l}\text { Sem história de } \\
\text { contato com pessoas } \\
\text { infectadas }\end{array}$ & \begin{tabular}{|l|} 
Diarreia, vômito, \\
febre, letargia, falta \\
de apetite, falta de ar, \\
pneumonia e choque, \\
desconforto respiratório \\
agudo e insuficiência \\
renal aguda, hipoxemia \\
\end{tabular} & $\begin{array}{l}\text { Consolidação visível no pulmão } \\
\text { direito, com opacidade em } \\
\text { vidro fosco. }\end{array}$ & $\begin{array}{l}\text { Amilase sérica A, } \\
\text { Isoenzima da CPK, } \\
\text { função hepática, } \\
\text { renal, coagulograma } \\
\text { e gasometria } \\
\text { alteradas }\end{array}$ \\
\hline $\begin{array}{l}\text { Kam KQ, et al }{ }^{(7)} \\
\text { Clin Infect. } \\
\text { Singapura, } 2020\end{array}$ & $\begin{array}{l}1 \text { paciente do sexo } \\
\text { masculino }\end{array}$ & $\begin{array}{l}\text { Relato de } \\
\text { caso }\end{array}$ & $\begin{array}{l}\text { Contato com familiar } \\
\text { COVID-19 positivo }\end{array}$ & Febre & Não refere & Neutropenia \\
\hline $\begin{array}{l}\text { Chan J, et } \mathrm{al}^{(21)} \\
\text { Lancet. } \\
\text { China, } 2020\end{array}$ & $\begin{array}{l}1 \text { paciente do sexo } \\
\text { masculino }\end{array}$ & $\begin{array}{l}\text { Relato de } \\
\text { caso }\end{array}$ & Aglomeração familiar & Febre, tosse & Não refere & $\begin{array}{l}\text { Fosfatase alcalina } \\
\text { aumentada }\end{array}$ \\
\hline $\begin{array}{l}\text { Liu M, et al } \mathrm{I}^{(22)} \\
\text { Comput Assist } \\
\text { Tomogr., China, } 2020\end{array}$ & \begin{tabular}{|l|}
5 pacientes \\
1 do sexo feminino \\
4 do sexo \\
masculino
\end{tabular} & $\begin{array}{l}\text { Série de } \\
\text { relatos de } \\
\text { caso }\end{array}$ & $\begin{array}{l}\text { Contato com familiar } \\
\text { COVID-19 positivo } \\
01 \text { não refere }\end{array}$ & Tosse, diarréia, febre & $\begin{array}{l}\text { Opacidade em vidro fosco na } \\
\text { Tomo } \\
02 \text { sem alterações }\end{array}$ & Não refere \\
\hline $\begin{array}{l}\text { Le HT, et al }{ }^{(23)} \\
\text { Lancet Child Adolesc } \\
\text { Heal., Vietnan, } 2020\end{array}$ & $\begin{array}{l}1 \text { paciente do sexo } \\
\text { feminino }\end{array}$ & $\begin{array}{l}\text { Relato de } \\
\text { caso }\end{array}$ & $\begin{array}{l}\text { Contato com familiar } \\
\text { COVID-19 positivo }\end{array}$ & $\begin{array}{l}\text { Congestão nasal, } \\
\text { rinorreia, } \\
\text { Febre baixa }\end{array}$ & Radiografia de tórax normal & $\begin{array}{l}\text { CPK, Lactato } \\
\text { desidrogenase, TGO, } \\
\text { TGP e Creatinina } \\
\text { elevados }\end{array}$ \\
\hline $\begin{array}{l}\text { Su L et al }\left.\right|^{(3)} \\
\text { Emerg Microbes } \\
\text { Infect. , China, } 2020\end{array}$ & $\begin{array}{l}9 \text { pacientes } \\
6 \text { do sexo feminino } \\
3 \text { do sexo } \\
\text { masculino }\end{array}$ & $\begin{array}{l}\text { Série de } \\
\text { relatos de } \\
\text { caso }\end{array}$ & $\begin{array}{l}\text { Contato com pessoas } \\
\text { infectadas, viagens a } \\
\text { área endêmica }\end{array}$ & $\begin{array}{l}\text { Febre, tosse, bronquite, } \\
\text { Pneumonia brônquica, }\end{array}$ & $\begin{array}{l}\text { Consolidação pulmonar e } \\
\text { opacidade em vidro fosco }\end{array}$ & $\begin{array}{l}\text { Aumento de CK-MB, } \\
\text { leucopenia }\end{array}$ \\
\hline $\begin{array}{l}\text { Zhou Y, et al(24) } \\
\text { Zhonghua Er Ke Za } \\
\text { Zhi, China, } 2020\end{array}$ & $\begin{array}{l}9 \text { pacientes } \\
04 \text { do sexo } \\
\text { masculino } \\
05 \text { do sexo } \\
\text { feminino }\end{array}$ & $\begin{array}{l}\text { Série de } \\
\text { relatos de } \\
\text { caso }\end{array}$ & $\begin{array}{l}\text { Viviam em } \\
\text { agrupamento familiar }\end{array}$ & Febre, tosse, rinorreia & $\begin{array}{l}\text { Inflamação pulmonar na TC } \\
\text { de tórax, lesões ao longo dos } \\
\text { feixes broncovasculares }\end{array}$ & $\begin{array}{l}\text { Leucocitose e } \\
\text { linfocitose }\end{array}$ \\
\hline
\end{tabular}


Continuação.

\begin{tabular}{|c|c|c|c|c|c|c|}
\hline Autores & Amostra & $\begin{array}{l}\text { Desenho do } \\
\text { estudo }\end{array}$ & Epidemiologia & Sinais clínicos & Exames de imagem & Exames laboratoriais \\
\hline $\begin{array}{l}\text { Zhang GX, et al } \mathrm{al}^{(25)} \\
\text { Zhonghua Er Ke Za } \\
\text { Zhi, China, } 2020\end{array}$ & $\begin{array}{l}2 \text { pacientes } \\
\text { Gêmeas do sexo } \\
\text { feminino }\end{array}$ & $\begin{array}{l}\text { Relato de } \\
\text { caso }\end{array}$ & $\begin{array}{l}\text { Contato com familiar } \\
\text { COVID-19 positivo }\end{array}$ & $\begin{array}{l}\text { Paciente a: febre, } \\
\text { tosse leve, amidalas } \\
\text { edemaciadas, } \\
\text { conjuntiva hiperemiada } \\
\text { Paciente b: febre, } \\
\text { tosse seca leve e } \\
\text { espirros, diarréia }\end{array}$ & $\begin{array}{l}\text { Paciente A: área subpleural } \\
\text { de ambos os pulmões com } \\
\text { aumento da densidade, forma } \\
\text { de cordão } \\
\text { Paciente B: Tomo nornal }\end{array}$ & $\begin{array}{l}\text { Lactato } \\
\text { desidrogenase e } \\
\text { Cardiomiosinase } \\
\text { elevadas }\end{array}$ \\
\hline $\begin{array}{l}\text { Qiu } \mathrm{H} \text {, et } \mathrm{al}^{(5)} \\
\text { Lancet Infect Dis. } \\
\text { China, } 2020\end{array}$ & $\begin{array}{l}36 \text { crianças } \\
13 \text { do sexo } \\
\text { feminino } \\
23 \text { do sexo } \\
\text { masculino }\end{array}$ & $\begin{array}{l}\text { Coorte } \\
\text { observacional }\end{array}$ & $\begin{array}{l}\text { Contato com familiar } \\
\text { infectado e exposição } \\
\text { à área epidêmica }\end{array}$ & $\begin{array}{l}\text { Febre, tosse, dor de } \\
\text { garganta, congestão } \\
\text { faríngea, vômito, } \\
\text { diarréia }\end{array}$ & $\begin{array}{l}\text { Opacidades pulmonares em } \\
\text { vidro fosco, Pneumonia e febre }\end{array}$ & $\begin{array}{l}\text { Leucopenia, } \\
\text { Linfopenia, CKMB, } \\
\text { Enzimas hepáticas e } \\
\text { PCR elevadas }\end{array}$ \\
\hline $\begin{array}{l}\text { Cai JH, et al }{ }^{(26)} \\
\text { Zhonghua Er Ke Za } \\
\text { Zhi, China, } 2020\end{array}$ & $\begin{array}{l}1 \text { paciente do sexo } \\
\text { masculino }\end{array}$ & \begin{tabular}{|l} 
Relato de \\
caso
\end{tabular} & $\begin{array}{l}\text { Viagem à área } \\
\text { epidêmica }\end{array}$ & $\begin{array}{l}\text { Febre, tosse leve, } \\
\text { secreções, falta de ar, } \\
\text { dificuldade em respirar, } \\
\text { náusea, anorexia, } \\
\text { vômito, diarréia, dor } \\
\text { abdominal, fadiga, } \\
\text { cefaléia }\end{array}$ & $\begin{array}{l}\text { Espessamento da textura } \\
\text { de ambos os pulmões na } \\
\text { radiografia de tórax }\end{array}$ & Dímero D 0,58 mg/L; \\
\hline $\begin{array}{l}\text { Wang D, et al(27) } \\
\text { Zhonghua Er Ke Za } \\
\text { Zhi, China, } 2020\end{array}$ & $\begin{array}{l}31 \text { crianças } \\
15 \text { do sexo } \\
\text { masculino } 16 \text { do } \\
\text { sexo feminino }\end{array}$ & $\begin{array}{l}\text { Coorte } \\
\text { retrospectiva }\end{array}$ & $\begin{array}{l}\text { Contato com } \\
\text { adulto confirmado, } \\
\text { assintomática e } \\
\text { aglomeração familiar }\end{array}$ & \begin{tabular}{|l|} 
Febre, amigdalite \\
supurativa \\
Assintomático $4(13 \%)$, \\
casos leve $13(42 \%)$ \\
casos normal $14(45 \%)$ \\
\end{tabular} & $\begin{array}{l}\text { Sombras e nódulos de vidro } \\
\text { fosco em TC }\end{array}$ & $\begin{array}{l}\text { Leucopenia, } \\
\text { leucocitose, PCR e } \\
\text { transaminase sérica } \\
\text { elevadas }\end{array}$ \\
\hline $\begin{array}{l}\text { Zheng F et al }{ }^{(28)} \\
\text { Curr Med Sci. China, } \\
2020\end{array}$ & \begin{tabular}{|l}
25 crianças \\
14 do sexo \\
masculino 11 do \\
sexo feminino
\end{tabular} & $\begin{array}{l}\text { Coorte } \\
\text { retrospectiva }\end{array}$ & $\begin{array}{l}\text { Viagem/residência } \\
\text { na área endêmica, } \\
\text { contato com } \\
\text { pessoa infectadas e } \\
\text { aglomeração familiar }\end{array}$ & \begin{tabular}{|l|} 
Febre, tosse seca, \\
diarréia, congestão \\
nasal, dispnéia, \\
Dor abdominal, vômitos, \\
infecção do trato \\
respiratório superior, \\
pneumonia leve
\end{tabular} & $\begin{array}{l}\text { Casos com comprometimento } \\
\text { bilateral e com } \\
\text { comprometimento unilateral }\end{array}$ & Linfopenia \\
\hline $\begin{array}{l}\text { Xia W, et al }{ }^{(29)} \\
\text { Pediatr Pulmonol. } \\
\text { China, } 2020\end{array}$ & $\begin{array}{l}20 \text { crianças } \\
13 \text { do sexo } \\
\text { masculino } 07 \text { do } \\
\text { sexo feminino }\end{array}$ & $\begin{array}{l}\text { Coorte } \\
\text { retrospectiva }\end{array}$ & $\begin{array}{l}\text { Contato com familiar } \\
\text { COVID-19 positivo }\end{array}$ & $\begin{array}{l}\text { Febre, diarreia, vomito } \\
\text { dor de garganta, } \\
\text { congestão nasal, dor, } \\
\text { taquipnéia fadiga }\end{array}$ & $\begin{array}{l}\text { Opacidade em vidro fosco, } \\
\text { Consolidação com o sinal } \\
\text { do halo circundante, lesões } \\
\text { nodulares }\end{array}$ & $\begin{array}{l}\text { Procalcitonina } \\
\text { elevada } \\
\text { Leucopenia, PCR e } \\
\text { CKMB aumentadas, } \\
\text { co-infecção }\end{array}$ \\
\hline $\begin{array}{l}\text { Feng K, et al }{ }^{(30)} \\
\text { Zhonghua Er Ke Za } \\
\text { Zhi, China, } 2020\end{array}$ & $\begin{array}{l}15 \text { crianças } \\
5 \text { do sexo } \\
\text { masculino } 10 \text { do } \\
\text { sexo feminino } \\
\end{array}$ & $\begin{array}{l}\text { Coorte } \\
\text { retrospectiva }\end{array}$ & $\begin{array}{l}\text { História de viagem a } \\
\text { área endêmica }\end{array}$ & $\begin{array}{l}\text { Febre } \\
10 \text { assintomáticas }\end{array}$ & $\begin{array}{l}\text { Opacidades nodulares em vidro } \\
\text { fosco }\end{array}$ & Sem alterações \\
\hline $\begin{array}{l}\text { Sun D, et al }{ }^{(31)} \\
\text { World J Pediatr. } \\
\text { China, } 2020\end{array}$ & $\begin{array}{l}8 \text { pacientes } \\
6 \text { do sexo } \\
\text { masculino } \\
2 \text { do sexo feminino }\end{array}$ & $\begin{array}{l}\text { Serie de } \\
\text { relatos de } \\
\text { casos }\end{array}$ & $\begin{array}{l}\text { Aglomeração familiar } \\
\text { transmissão não } \\
\text { identificada }\end{array}$ & $\begin{array}{l}\text { Tosse, náusea, vômito, } \\
\text { diarréia fadiga, } \\
\text { mialgia, dor de cabeça, } \\
\text { constipação, polipnéia }\end{array}$ & $\begin{array}{l}\text { Opacidade em vidro fosco } \\
\text { Derrame pleural, pneumonias }\end{array}$ & $\begin{array}{l}\text { Procalcitonina, } \\
\text { PCR, lactato } \\
\text { desidrogenase, e TGO } \\
\text { elevadas }\end{array}$ \\
\hline $\begin{array}{l}\text { Liu W, et al(32) } \\
N \text { Engl J Med. } \\
\text { China, } 2020\end{array}$ & $\begin{array}{l}6 \text { pacientes } \\
2 \text { do sexo } \\
\text { masculino } \\
4 \text { do sexo feminino } \\
\end{array}$ & $\begin{array}{l}\text { Relato de } \\
\text { caso }\end{array}$ & $\begin{array}{l}\text { Viagem à area } \\
\text { endêmica }\end{array}$ & $\begin{array}{l}\text { Febre, tosse e vômito } \\
\text { Pneumonia }\end{array}$ & Opacidade em vidro fosco & Leucopenia \\
\hline $\begin{array}{l}\text { Zeng LK, et al }\left.\right|^{(33)} \\
\text { Zhonghua Er Ke Za } \\
\text { Zhi., China, } 2020\end{array}$ & $\begin{array}{l}1 \text { paciente do } \\
\text { sexo masculino }\end{array}$ & $\begin{array}{l}\text { Relato de } \\
\text { caso }\end{array}$ & $\begin{array}{l}\text { Contato com familiar } \\
\text { COVID-19 positivo }\end{array}$ & Vômito, tosse, diarréia & $\begin{array}{l}\text { Sobreamento em vidro fosco } \\
\text { nos dois pulmões }\end{array}$ & $\begin{array}{l}\text { Função hepática, } \\
\text { renal, coagulação, } \\
\text { urina e fezes normais }\end{array}$ \\
\hline $\begin{array}{l}\text { Wang J, et al }{ }^{(34)} \\
\text { Zhonghua Er Ke Za } \\
\text { Zhi., China, } 2020\end{array}$ & $\begin{array}{l}1 \text { paciente do } \\
\text { sexo masculino }\end{array}$ & $\begin{array}{l}\text { Relato de } \\
\text { caso }\end{array}$ & $\begin{array}{l}\text { Contato com familiar } \\
\text { COVID-19 positivo }\end{array}$ & Vômito, tosse, diarréia & $\begin{array}{l}\text { Opacidade em vidro fosco } \\
\text { bilateral }\end{array}$ & Sem informação \\
\hline $\begin{array}{l}\text { Xu Y, et al( }{ }^{(35)} \\
\text { Nature Medicine } \\
\text { China, } 2020\end{array}$ & $\begin{array}{l}10 \text { pacientes } \\
7 \text { do sexo } \\
\text { masculino } \\
3 \text { do sexo feminino }\end{array}$ & $\begin{array}{l}\text { Serie de } \\
\text { relatos de } \\
\text { casos }\end{array}$ & $\begin{array}{l}\text { Contato com familiar } \\
\text { infectado e Viagem à } \\
\text { area endêmica }\end{array}$ & Vômito, tosse, diarréia & Opacidade em vidro fosco & $\begin{array}{l}\text { Leucocitose e função } \\
\text { hepática alterada }\end{array}$ \\
\hline $\begin{array}{l}\text { Lu X, et al. }{ }^{(36)} \\
\text { The New England } \\
\text { Journal Of Medicine } \\
\text { China, } 2020\end{array}$ & $\begin{array}{l}171 \text { pacientes } \\
104 \text { do sexo } \\
\text { masculino } \\
67 \text { do sexo } \\
\text { feminino }\end{array}$ & $\begin{array}{l}\text { Carta ao } \\
\text { Editor }\end{array}$ & $\begin{array}{l}\text { Membros da família } \\
\text { confirmados, } \\
\text { suspeitos, Cluster } \\
\text { familiar, Fonte não } \\
\text { identificada }\end{array}$ & $\begin{array}{l}\text { Infecção do trato } \\
\text { respiratório superior, } \\
\text { febre, diarreia, fadiga, } \\
\text { vomito, congestão } \\
\text { nasal, taquicardia, } \\
\text { taquipneia, tosse. } \\
\end{array}$ & $\begin{array}{l}\text { Opacidades em vidro fosco } \\
\text { Sombreamento irregular local } \\
\text { Sombreamento irregular } \\
\text { bilateral } \\
\text { Pneumonia }\end{array}$ & Não referiu \\
\hline
\end{tabular}


Tabela 1. Características clínicas, epidemiológicas, exames de imagem e laboratoriais de 374 pacientes com diagnóstico de infecção por SARS-CoV2

\begin{tabular}{|c|c|}
\hline Características & $\mathrm{n}(\%)$ \\
\hline Mediana da idade em anos & $10(0,1-15)$ \\
\hline \multicolumn{2}{|l|}{ Sexo } \\
\hline Masculino & $211(56,4)$ \\
\hline Feminino & $163(43,6)$ \\
\hline \multicolumn{2}{|l|}{ Diagnóstico } \\
\hline Infecção assintomática & $219(58,5)$ \\
\hline Pneumonia & $120(32)$ \\
\hline Infecção do trato respiratório superior & $35(9,4)$ \\
\hline \multicolumn{2}{|l|}{ Epidemiologia } \\
\hline Aglomeração familiar & $169(45,2)$ \\
\hline Membro da família confirmado & 146(39) \\
\hline Área Epidêmica & $18(4,8)$ \\
\hline Fonte não identificada da infecção & $18(4,8)$ \\
\hline Contato com outro caso suspeito & $10(2,7)$ \\
\hline \multicolumn{2}{|l|}{ Sinais e sintomas } \\
\hline Tosse & $166(44,4)$ \\
\hline Temperatura menor que $37,5^{\circ} \mathrm{C}$ & $100(26,7)$ \\
\hline Temperatura entre 38,1 e $39^{\circ} \mathrm{C}$ & $96(25,7)$ \\
\hline Eritema faríngeo & $79(21,1)$ \\
\hline Temperatura entre 37,5 e $38^{\circ} \mathrm{C}$ & $53(14,2)$ \\
\hline Diarreia & $41(11)$ \\
\hline Vômito & $34(9,09)$ \\
\hline Fadiga & $30(8,02)$ \\
\hline Temperatura maior que $39^{\circ} \mathrm{C}$ & $30(8,02)$ \\
\hline Rinorreia & $29(7,7)$ \\
\hline Congestão nasal & $28(7,5)$ \\
\hline Tempo de eliminação do vírus pela via aérea em dias & $23(7-23)$ \\
\hline Tempo de eliminação do vírus nas fezes em dias & $18(10->30)$ \\
\hline Tempo da internação em dias & $15(7-25)$ \\
\hline Duração média da febre em dias & $3(1-10)$ \\
\hline \multicolumn{2}{|l|}{ Achados em exames de imagens } \\
\hline Opacidade em vidro fosco & $138(36,9)$ \\
\hline Sombreamento irregular local & $40(10,7)$ \\
\hline Sombreamento irregular bilateral & $32(8,5)$ \\
\hline \multicolumn{2}{|l|}{ Complicações } \\
\hline Síndrome do desconforto respiratória & $4(01)$ \\
\hline Choque & $2(0,5)$ \\
\hline \multicolumn{2}{|l|}{ Exames laboratoriais } \\
\hline Creatinoquinase - MB aumentada & $32(8,5)$ \\
\hline Proteína $\mathrm{C}$ reativa alterada & $30(08)$ \\
\hline Contagens de glóbulos brancos diminuído & $11(2,9)$ \\
\hline Função hepática alterada & $10(2,7)$ \\
\hline Contagens de glóbulos brancos aumentadas & $9(2,4)$ \\
\hline Função renal alterada & $5(1,3)$ \\
\hline
\end{tabular}

$\mathrm{n}$ apresentado em frequência (\%); mediana (range)

\section{Características clínicas}

As pesquisas primárias incluíram principalmente pacientes previamente hígidos com infecção por SARS-CoV2, e identificaram 219(58.5\%) pacientes que apresentaram a doença de forma assintomática. Além disto, em quatro estudos. . $^{(1,14,15,17)}$ os pacientes apresentaram doença de base como: Leucemia linfoblástica aguda, Hidronefrose, Cardiopatia congênita, Desnutrição e Doenças Metabólicas.

Os principais sinais clínicos apresentados pelos pacientes foram tosse, eritema faríngeo e alteração da temperatura corpórea. Além disto, a mediana para eliminação do vírus pelas fezes foi de 18 dias $(10$ - >30) e para eliminação do vírus pelas vias aérea de 20 dias. . $^{(7-23)}$

O maior pico de temperatura descrito foi de $40^{\circ} \mathrm{C}$, com mediana de tempo de duração de 3 dias (1-10); já para a internação a mediana foi de 15 dias. . $^{(-25)}$

Quanto à história epidemiológica, observou-se que $169(45.2 \%)$ pacientes viviam em aglomeração familiar, $146(39 \%)$ tiveram contato com membro da família infectado por COVID-19, 18(4.8\%) tinha histórico de viagem à área epidêmica, 10(2.7\%) tiveram contato com outro caso suspeito de COVID-19 e apenas $18(4,3 \%)$ não tinham fonte identificada para a infecção. A análise dos dados revelou que 24(6,4\%) dos pacientes descritos nos relatos primários utilizaram oxigênio.

As principais complicações descritas foram internação em unidade de terapia intensiva, ${ }^{(12)} \mathrm{e}$ uso de ventilação mecânica, ${ }^{(12-31)}$ derrame pleural, ${ }^{(9)}$ choque séptico e óbito. ${ }^{(12,13)}$

\section{Achados laboratoriais e de imagens}

Dos relatos que fizeram a dosagem da isoenzima CK-MB, 32 (8,5\%) apresentaram valor aumentado, 9 pacientes $(2,4 \%)$ apresentaram leucocitose e $11(2,9 \%)$ leucopenia. Aumento da proteína $\mathrm{C}$ reativa foi observada em 30 pacientes (8\%), 5(1.3\%) apresentaram alteração da função renal (aumento da creatinina e da uréia), e 10(2,7\%) apresentaram alteração da função hepática. Quanto ao diagnóstico, 120 dos pacientes diagnosticados com SARS-CoV2 (32\%), apresentaram pneumonia leve evidenciada em radiografia de tórax ou em imagem de tomografia de tórax, cujas principais alterações encontradas foram opacidade em vidro fosco, sombreamento irregular local, sombreamento irregular bilateral. ${ }^{(32-36)}$

\section{Discussão}

Até o momento, o Coronavírus (SARS-CoV-2) foi responsável por mais de 18.142.718 infecções e 691.013 
mortes em todo o mundo, conforme dados disponíveis na página da Organização Pan-Americana de Saúde em 04 de agosto de 2020. ${ }^{(37)}$ Contudo, dados referentes às características epidemiológicas e características clínicas em crianças infectadas ainda são limitadas, e as principais publicações no momento são relatos ou série de relatos, coorte retrospectiva e observacional. ${ }^{(17-19)}$

O resultado desta revisão mostrou que as crianças do sexo masculino foram as mais acometidas, corroborando com a literatura, que evidencia níveis mais altos de ECA2 nas células alveolares dos homens, quando comparados às mulheres, e maiores taxas de internação. $(8,9,24,25)$

A análise das pesquisas primárias mostrou que pacientes pediátricos adquiriram infecções principalmente por meio de contato próximo com seus pais ou outros membros da família com infecção SARS-CoV-2 e que crianças hígidas tendem apresentar sintomas mais leves e/ou apresenta a doença de forma assintomática e/ou oligossintomática.

Não foram descritos casos de transmissão vertical, apenas o relato de um bebê com 19 dias de vida. ${ }^{(32-34)} \mathrm{A}$ mãe apresentou febre e tosse paroxística um dia antes do parto, e após coleta laboratorial verificou-se que a mãe estava com SARS-CoV-2. O bebê teve histórico de recusa do leite e diarreia cerca de 4 a 5 vezes por dia, e temperatura corporal máxima de $39^{\circ} \mathrm{C}$ durante $24 \mathrm{~h}$. A pesquisa orofaríngea e nas fezes foi positiva no terceiro dia da sintomatologia, e o vírus ficou 9 dias no organismo.

Apesar de não haver confirmação de transmissão vertical, há um alto contágio a partir de contato com pessoas infectadas, e somado à aglomeração familiar, esta é uma característica epidêmica importante descrita nos estudos para ocorrência deste surto. ${ }^{(15,16)}$

Outro achado dessa revisão foi que a maioria dos pacientes pediátricos, assim como nos adultos, apresentava swab positivo após 2 a 3 dias dos primeiros sintomas, o que sugere um período de incubação para infecção por SARS-CoV-2 de 3 a 4 dias, podendo variar de 1 a 14 dias. ${ }^{(1,9)}$

Um aspecto importante que deve ser considerado na pediatria é a longa duração da eliminação do vírus nas fezes, principalmente para os que utilizam fralda e os que estão hospitalizados, pois esta fonte de transmissão tem recebido menos atenção dos meios de comunicação e nos informativos do que a transmissão por via aérea ou contato.
Em comparação com os adultos infectados, a maioria dos pacientes pediátricos parece ter um curso clínico da doença mais leve e de forma assintomática, com pequeno número de alterações laboratoriais e/ou alteração de funções orgânicas. ${ }^{(12-19)}$ Todavia, algumas medidas devem ser consideradas para a assistência de enfermagem a esses pacientes, em especial quando hospitalizados em unidades de terapia intensiva, como: ${ }^{(10,38)}$

- assistência ao paciente: o ideal é um profissional exclusivo para cuidar de paciente com infecção por SARS-CoV-2. Na impossibilidade deste, é de extrema importância que o profissional faça adequadamente a higienização das mãos, paramentação, desparamentação correta e lavagem de mãos. O profissional deve utilizar máscara cirúrgica durante assistência e máscara N95 quando for realizar procedimentos que gerem aerossóis;

- planejamento adequado do transporte de paciente: se entubado, manter sistema fechado de aspiração e aspirar somente se necessário, inclusive realizar avaliação prévia de necessidade de aspiração pré-transporte. Para paciente em uso de outros dispositivos de oxigenioterapia é obrigatório o uso de máscara cirúrgica. O profissional deve utilizar máscara cirúrgica durante transporte e máscara N95 quando for realizar procedimentos que gerem aerossóis;

- balança de uso individual: é imprescindível para o paciente, devido à eliminação e transmissão do vírus pelas fezes, assim como a manutenção de um hamper na antessala do isolamento onde o paciente se encontra para o descarte adequado das roupas utilizadas durante hospitalização;

- cuidados com dispositivos: quando há necessidade de acesso vascular, deve-se evitar punção de veia jugular devido ao maior risco de contaminação do profissional, priorizando a punção de membros superiores;

- aleitamento materno: oferecer máscara e orientar higiene adequada das mãos antes de iniciar o aleitamento;

- humanização durante hospitalização: nem todo paciente na unidade de terapia intensiva está entubado ou sedado por conta da infecção por SARS-CoV-2. A prescrição de cuidados deve considerar este fato de modo que o paciente precisa, 
principalmente por conta do isolamento, de atividades lúdicas, permitidas de acordo com seu estado geral. A Organização Pan-americana de Saúde orienta os profissionais a oferecerem materiais para desenhos às crianças, pois através destes elas conseguem exteriorizar sentimentos e pensamentos. Também é interessante a aplicação de escalas de ansiedade conforme as faixas etárias, para direcionar os cuidados e disponibilizar recursos digitais para interação com familiares durante hospitalização;

- cuidado centrado na criança e família: é de suma importância que o paciente seja orientado sobre o porquê do seu isolamento na unidade e proibição de visitas, de acordo com a faixa etária e seu grau de compreensão das informações. Os pais também devem receber tais orientações;

- atenção ao paciente adolescente: conversar com o adolescente sem a presença do acompanhante diariamente para verificar possíveis alterações comportamentais oriundas do processo de hospitalização, principalmente se o mesmo apresenta doença de base;

Outro aspecto importante atrelado à informação é a disponibilização de livretos explicativos, confeccionados de forma simples, com ilustrações que facilitem a compreensão dos pacientes quanto à infecção e medidas utilizadas no seu tratamento.

A saúde mental também deve ser considerada pelos profissionais de saúde no atendimento desses pacientes, pois constata-se que as crianças estão sendo fortemente impactados emocional e psicologicamente pela pandemia, manifestando diversos problemas comportamentais. ${ }^{(39)}$ Nenhum dos artigos desta revisão abordou esta questão, o que nos remete à necessidade de recomendar uma anamnese e histórico de enfermagem detalhados, para embasar as demais etapas do processo de enfermagem, incluindo a saúde mental desde a admissão até a alta.

Por fim, a alta dos pacientes também deve conter informações referentes aos cuidados diários, uma vez que ainda vivemos um momento de pandemia, incluindo a manutenção do isolamento social, rotinas de higienização de alimentos e ambientes, atividades que minimizem o aparecimento de sinais ou sintomas de depressão e estresse oriundos deste período.

\section{Conclusão}

Pacientes pediátricos com infecção por SARS-CoV-2 tendem a apresentar sintomas clínicos e achados de imagem leves, não tão típicos quanto os adultos, o que demanda um diagnóstico de COVID-19 baseado nos achados de imagem, juntamente com o histórico epidemiológico e pesquisa em swab orofaríngeo, fezes e urina.

A assistência de enfermagem deve contemplar medidas específicas para o combate ao SARS-CoV-2, com ênfase na paramentação e desparamentação adequadas afim de manter a saúde física e emocional dos profissionais, e continuidade do cuidado prestado de maneira segura e com qualidade.

\section{Referências}

1. Ye G, Pan Z, Pan Y, Deng Q, Chen L, Li J, et al. Clinical characteristics of severe acute respiratory syndrome coronavirus 2 reactivation. J Infect. 2020;80(5):e14-7.

2. Deng $\mathrm{SQ}$, Peng $\mathrm{HJ}$. Characteristics of and public health responses to the coronavirus disease 2019 Outbreak in China. J Clin Med. 2020;9(2):575.

3. Su L, Ma X, Yu H, Zhang Z, Bian P, Han Y, et al. The different clinical characteristics of corona virus disease cases between children and their families in China - the character of children with COVID-19. Emerg Microbes Infect. 2020;9(1):707-13.

4. Rodell CB. An ACE therapy for COVID-19. Sci TransI Med. 2020;12(541):eabb5676.

5. Qiu H, Wu J, Hong L, Luo Y, Song Q, Chen D. Clinical and epidemiological features of 36 children with coronavirus disease 2019 (COVID-19) in Zhejiang, China: an observational cohort study. Lancet Infect Dis. 2020;20(6):689-96.

6. Liu Y, Yan LM, Wan L, Xiang TX, Le A, Liu JM, et al. Viral dynamics in mild and severe cases of COVID-19. Lancet Infect Dis. 2020;20(6):656-7.

7. Kam KQ, Yung CF, Cui L, Tzer Pin Lin R, Mak TM, Maiwald M, et al. A well infant with coronavirus disease 2019 with high viral load. Clin Infect Dis. 2020;71(15):847-9.

8. Zhang T, Cui X, Zhao X, Wang J, Zheng J, Zheng G, et al. Detectable SARS-CoV-2 viral RNA in feces of three children during recovery period of COVID-19 pneumonia. J Med Virol. 2020;92(7):909-14.

9. Medeiros EA. Challenges in the fight against the COVID-19 pandemic in university hospitals. Rev Paul Pediatr. 2020;38:e2020086.

10. Sociedade Brasileira de Pediatria (SBP). Aleitamento Materno em tempos de COVID-19 - recomendações na maternidade e após a alta publicada em 22 de Maio de 2020. São Paulo: SBP; 2020 [citado 2020 Jun 13]. Disponível em https://www.sbp.com.br/ documentoscientificos/

11. Joanna Briggs Institute (JBI). Methodology for JBI scoping reviews - Joanna Briggs 2015. JBI; 2015 [cited 2015 Jul 10]. Available from:http://joannabriggs.org/assets/docs/ sumari/ReviewersManual_Methodology-for-JBI-Scoping-Reviews_2015_v2.pdf

12. Cao Q, Chen YC, Chen CL, Chiu CH. SARS-CoV-2 infection in children: transmission dynamics and clinical characteristics. J Formos Med Assoc. 2020;119(3):670-3.

13. Jiehao $\mathrm{C}$, Jin X, Daojiong L, Zhi Y, Lei X, Zhenghai Q, et al. A case series of children with 2019 novel coronavirus infection: clinical and epidemiological features. Clin Infect Dis. 2020;71(6):1547-51.

14. Li Y, Guo F, Cao Y, Li L, Guo Y. Insight into COVID-2019 for pediatricians. Pediatr Pulmonol. 2020 May;55(5):E1-4.

15. Ji LN, Chao S, Wang YJ, Li XJ, Mu XD, Lin MG, et al. Clinical features of pediatric patients with COVID-19: a report of two family cluster cases. World J Pediatr. 2020;16(3):267-70.

16. Park JY, Han MS, Park KU, Kim JY, Choi EH. First pediatric case of coronavirus disease 2019 in Korea. J Korean Med Sci. 2020;35(11):e124. 
17. Cui Y, Tian M, Huang D, Wang X, Huang Y, Fan L, et al. A 55-day-old female infant infected with 2019 novel coronavirus disease: presenting with pneumonia, liver injury, and heart damage. J Infect Dis. 2020;221(11):1775-81.

18. Tang A, Tong ZD, Wang HL, Dai YX, Li KF, Liu JN, et al. Detection of novel coronavirus by RT-PCR in stool specimen from asymptomatic child, China. Emerg Infect Dis. 2020;26(6):1337-9.

19. Zhang YH, Lin DJ, Xiao MF, Wang JC, Wei Y, Lei ZX, et al. [2019 novel coronavirus infection in a three-month-old baby]. Zhonghua Er Ke Za Zhi. 2020;58(3):182-4. Chinese.

20. Chen F, Liu ZS, Zhang FR, Xiong RH, Chen Y, Cheng XF, et al. [First case of severe childhood novel coronavirus pneumonia in China]. Zhonghua Er Ke Za Zhi. 2020;58(3):179-82. Chinese.

21. Chan JF, Yuan S, Kok KH, To KK, Chu H, Yang J, et al. A familial cluster of pneumonia associated with the 2019 novel coronavirus indicating person-to-person transmission: a study of a family cluster. Lancet. $2020 ; 395(10223): 514-23$.

22. Liu M, Song Z, Xiao K. High-resolution computed tomography manifestations of 5 pediatric patients with 2019 novel coronavirus. J Comput Assist Tomogr. 2020;44(3):311-3.

23. Le HT, Nguyen LV, Tran DM, Do HT, Tran HT, Le YT, et al. The first infant case of COVID-19 acquired from a secondary transmission in Vietnam. Lancet Child Adolesc Health. 2020;4(5):405-6.

24. Zhou Y, Yang GD, Feng K, Huang H, Yun YX, Mou XY, et al. [Clinical features and chest CT findings of coronavirus disease 2019 in infants and young children]. Zhongguo Dang Dai Er Ke Za Zhi. 2020;22(3):215-20. Chinese.

25. Zhang GX, Zhang AM, Huang L, Cheng LY, Liu ZX, Peng XL, et al. [Twin girls infected with SARS-CoV-2]. Zhongguo Dang Dai Er Ke Za Zhi. 2020;22(3):221-5. Chinese.

26. Cai JH, Wang XS, Ge YL, Xia AM, Chang HL, Tian H, et al. [First case of 2019 novel coronavirus infection in children in Shanghai]. Zhonghua Er Ke Za Zhi. 2020;58(0):E002. Chinese.

27. Wang D, Ju XL, Xie F, Lu Y, Li FY, Huang HH, et al. [Clinical analysis of 31 cases of 2019 novel coronavirus infection in children from six provinces (autonomous region) of northern China]. Zhonghua Er Ke Za Zhi. 2020;58(4):269-74. Chinese.

28. Zheng F, Liao C, Fan QH, Chen HB, Zhao XG, Xie ZG, et al. Clinical Characteristics of children with coronavirus disease 2019 in Hubei, China. Curr Med Sci. 2020;40(2):275-80.
29. Xia W, Shao J, Guo Y, Peng X, Li Z, Hu D. Clinical and CT features in pediatric patients with COVID-19 infection: different points from adults. Pediatr Pulmonol. 2020;55(5):1169-74.

30. Feng K, Yun YX, Wang XF, Yang GD, Zheng YJ, Lin CM, et al. [Analysis of CT features of 15 children with 2019 novel coronavirus infection]. Zhonghua Er Ke Za Zhi. 2020;58:EO07. Chinese.

31. Sun D, Li H, Lu XX, Xiao H, Ren J, Zhang FR, et al. Clinical features of severe pediatric patients with coronavirus disease 2019 in Wuhan: a single center's observational study. World J Pediatr. 2020;16(3):251-9.

32. Liu W, Zhang Q, Chen J, Xiang R, Song H, Shu S, et al. Detection of COVID-19 in children in early january 2020 in Wuhan, China. N Engl J Med. 2020;382(14):1370-1.

33. Zeng LK, Tao XW, Yuan WH, Wang J, Liu X, Liu ZS. [First case of neonate infected with novel coronavirus pneumonia in China]. Zhonghua Er Ke Za Zhi. 2020;58:E009. Chinese.

34. Wang J, Wang D, Chen GC, Tao XW, Zeng LK. [SARS-CoV-2 infection with gastrointestinal symptoms as the first manifestation in a neonate]. Zhongguo Dang Dai Er Ke Za Zhi. 2020;22(3):211-4. Chinese.

35. Xu Y, Li X, Zhu B, Liang H, Fang C, Gong Y, et al. Characteristics of pediatric SARSCoV-2 infection and potential evidence for persistent fecal viral shedding. Nat Med. 2020;26(4):502-5.

36. Lu X, Zhang L, Du H, Zhang J, Li YY, Qu J, et al.; Chinese Pediatric Novel Coronavirus Study Team. SARS-CoV-2 infection in children. N Engl J Med. 2020 ;382(17):1663-5.

37. Organização Pan-Americana de Saúde (OPAS). Folha informativa COVID-19. OPAS; c2020 [atualizado 2020 Set 23; citado 2020 Set 25]. Disponível em https:// wmw.paho.org/pt/covid19

38. Agência Nacional de Vigilância Sanitária (ANVISA). Orientações para senviços de saúde: medidas de prevenção e controle que devem ser adotadas durante a assistência aos casos suspeitos ou confirmados de infecção pelo novo coronavírus (SARS-CoV-2) Nota Técnica $n^{0}$ 04-2020. Versão 1.13 [citado 2020 Set 24]. Disponivel em: http://portal.anvisa.gov.br/ documents/33852/271858/Nota+T\%C3\%A9cnica+n+04-2020+GVIMS-GGTES-ANVISAATUALIZADA/ab598660-3de4-4f14-8e6f-b9341c196b28

39. Jiao WY, Wang LN, Liu J, Fang SF, Jiao FY, Pettoello-Mantovani M, et al. behavioral and emotional disorders in children during the COVID-19 epidemic. J Pediatr. 2020;221:264266.e1. 